Original Research Article

\title{
Knowledge and perception about generic drugs in patients coming to OPD of tertiary care centre
}

\author{
Mehul Y. Choulera, Dashputra Amruta V.*, Archana S. Borkar, Amit P. Date
}

Department of Pharmacology, NKP Salve Institute of Medical Sciences, Nagpur, Maharashtra, India

Received: 14 March 2018

Accepted: 07 April 2018

\section{*Correspondence to:}

Dr. Dashputra Amruta V., Email: avdashputra@gmail.com

Copyright: (C) the author(s), publisher and licensee Medip Academy. This is an openaccess article distributed under the terms of the Creative Commons Attribution NonCommercial License, which permits unrestricted noncommercial use, distribution, and reproduction in any medium, provided the original work is properly cited.

\begin{abstract}
Background: In an era of rapidly rising health care costs generic medicines provide a less expensive alternative to branded medicines. In addition to reducing the overall health care expenditure, it has been shown to improve adherence. Objective was to study knowledge and perception about generic drugs among patients coming to outpatient department of tertiary care centre.

Methods: After ethical approval a cross sectional questionnaire based study was conducted. Patients $(n=71)$ were interviewed according to questionnaire in vernacular language by investigator to fill questionnaire.

Results: About $28 \%$ people think that price of generic drug is less than a branded drug while nearly $61 \%$ of people don't know of it. Only $18.85 \%$ participants had taken generic medicine. Trusting efficacy of generic drugs only 30 participants were in favour it. Even they have not seen or heard publicity of generic drugs $(61.97 \%)$. They $(60.56 \%)$ opined that generic drugs never prescribe in our country.

Conclusions: Limitation in knowledge and perception about generic medicines has been seen among participants.
\end{abstract}

Keywords: Branded drug, Cost effectiveness, Generic drug, Janaushadhi store

\section{INTRODUCTION}

Drugs play very important role in health protection and recovery from disease. Around one third of the world population has difficulties in accessing medication due to high cost of drugs. ${ }^{1}$ The most crucial element which restrict access to medicines is medicine pricing. ${ }^{2}$ Most countries are facing escalating health care expenditures. Escalating costs and affordability of medicine for both governments and patients has become a global challenge. In an era of rapidly rising health care costs generic medicines provide a less expensive alternative to branded medicines. Generic drugs are an alternative to brand drugs in many countries including United States (USA), Germany and developing country like India. ${ }^{3}$ Use of generic medicines contributed to substantial savings in medicine expenditure. ${ }^{4}$ In addition to reducing the overall health care expenditure, use of generic medicine can reduce patients out of pocket costs and has been shown to improve adherence. ${ }^{5}$

Generic drug is defined as a medication that is produced freely after expiry of patent protecting the branded product, necessarily being similar to the branded drug (Reference drug) in bioequivalence in order to obtain the same therapeutic effect. ${ }^{6,7}$ This a study conducted in Spain. Showed that $98.8 \%$ of patients agreed to switch from brand drugs to generics after receiving information on generics. This indicates that knowledge about generic drugs is a major factor guiding their choice by consumers. Generic drugs are an alternative to brand drugs for acquiring good quality medications at affordable prices for large segment of population. ${ }^{8}$ Hence this project is planned to assess knowledge and perception of generic drugs among patients population coming to outpatient department of tertiary health care institute. 
Objective was to study knowledge and perception about generic drugs among patients coming to outpatient department of tertiary health care institute.

\section{METHODS}

After ethical approval a cross sectional questionnaire based study was conducted at tertiary health care centre of central India. Participants for the study were patients coming to outpatient department of tertiary health care centre. Patients willing to participate in study were included after informed consent. Patients $(n=71)$ were interviewed according to questionnaire in vernacular language by investigator to fill questionnaire.

The questionnaire consisted of two sections. The first section of the questionnaire was on participant's demographic characteristics. The second section in initial part had questions having affirmative or negative answers exploring participant's knowledge on generic medicines. Subsequent portion of second section of questionnaire had questions, exploring views on generic medicines.

\section{Statistical analysis}

Data was analyzed and conclusions were drawn by percentage with Epi-info software version 6.

\section{RESULTS}

\section{Demographic details}

In this study, 41 females (57.75\%) and 30 males (42.25\%) participated (total $n=71$ ). Among total participants 63 were from urban and 8 from rural background. In age group highest participants were between $21-30$ years $(55 \%), 31$ 40 years $(21 \%), 51-60$ years $(20 \%)$, then $41-50$ years $(3 \%)$ and least from 11-20 years of age (1\%). Among them $37(52.1 \%)$ participants were married as compared to 34 $(47.89 \%)$ of unmarried participants. Monthly income of $42 \%$ participants were between $30,000 /-$ to $60,000 /$-per month, close to it $41 \%$ having less than $30,000 /-$ per month income, while $17 \%$ participants had more than $60,000 /-$ per month income.

Table 1: Patient's knowledge on generic drugs $(n=71)$.

\begin{tabular}{|lll|}
\hline Item & Yes & No \\
\hline Are you taking any medications at present? & $30(42.25 \%)$ & $41(57.75 \%)$ \\
\hline Medications taken for continuous use? & $30(42.25 \%)$ & $41(57.75 \%)$ \\
\hline Have you heard of generic drugs? & $25(35.21 \%)$ & $46(64.79 \%)$ \\
\hline Received information on generic drugs? & $25(35.21 \%)$ & $46(64.79 \%)$ \\
\hline Already taken generic drug? & $13(18.31 \%)$ & $58(81.69 \%)$ \\
\hline Prefer generic drug over branded drug? & $29(40.85 \%)$ & $42(59.15 \%)$ \\
\hline Trust efficiency of generic drugs? & $30(42.25 \%)$ & $41(57.75 \%)$ \\
\hline Physician prescribed a branded drug and pharmacist offers cheaper generic, agreed? & $36(50.70 \%)$ & $35(49.30 \%)$ \\
\hline Awareness about Jan Aushadhi store? & $39(54.93 \%)$ & $32(45.07 \%)$ \\
\hline
\end{tabular}

Table 2: Patient's attitude on generic drugs $(n=71)$.

\begin{tabular}{|llllll|}
\hline Item & Never & Rarely & Sometimes & Always & Don't Know \\
\hline Your physician prescribes generic drug & $13(18.31 \%)$ & $6(8.45 \%)$ & $16(22.54 \%)$ & $5(7.04 \%)$ & $31(43.66 \%)$ \\
\hline Prefer buying of generic drugs. & $36(50.70 \%)$ & $9(12.68 \%)$ & $15(21.13 \%)$ & $6(8.45 \%)$ & $5(7.04 \%)$ \\
\hline $\begin{array}{l}\text { Generic drugs have side effects as } \\
\text { compared to branded drug. Agree? }\end{array}$ & - & $25(35.21 \%)$ & $8(11.27 \%)$ & $4(5.63 \%)$ & $34(47.89 \%)$ \\
\hline Publicity of generic drugs & $44(61.97 \%)$ & $17(23.94 \%)$ & $9(12.68 \%)$ & $1(1.41 \%)$ & - \\
\hline $\begin{array}{l}\text { Are generic drugs well prescribed in our } \\
\text { country? }\end{array}$ & $43(60.56 \%)$ & - & - & $\begin{array}{l}14 \\
(19.72 \%)\end{array}$ & $14(19.72 \%)$ \\
\hline $\begin{array}{l}\text { Are generic drugs available in } \\
\text { pharmacies? }\end{array}$ & $10(14.08 \%)$ & $12(16.90 \%)$ & $12(16.90 \%)$ & $13(18.31 \%)$ & $24(33.80 \%)$ \\
\hline
\end{tabular}

Out of total 71 people being surveyed $76 \%$ (54) people purchase more than 3 medications (Tab/day) each month while least being 4\% (3) purchasing 1 medication each month.

About $82 \%$ (58) people buy medications from pharmacy/chemist shop while 16\% (11) of them buy from government healthcare unit and remaining don't purchase or take medications.

About $28 \%$ people think that price of generic drug is less than a branded drug while nearly $61 \%$ (43) of people don't know of it. Compared to branded drug $20 \%$ participants thought that generic drugs are good in quality whereas $58 \%$ participants don't know about it. 
In present study $25(42.25 \%)$ of participants knew and received information on generic medicine. This shows that remaining $46(64.79 \%)$ were not familiar with generic drugs. Only $13(18.85 \%)$ participants had taken generic medicine as compared to $58(81.15 \%)$ participants who didn't experience generic medicine. Given a choice 29 $(40.85 \%)$ participants prefer generic drugs over branded drugs. Opinion about physician prescribing branded drug and pharmacist offering generic drugs, 36 participants gave assertive response, whereas 35 participants gave negative response. In trusting efficacy of generic drugs only 30 participants were having favourable response. Awareness about Jan Aushadhistore showed that 39 $(54.93 \%)$ participants were aware as compared to 32 $(45.07 \%)$ who didn't know about it.

To explore perception about generic drugs, it showed only $5(7.04 \%)$ participants said that generic drugs were always prescribed by clinician whereas 31 participants didn't know of it while remaining gave negative response.

Out of total 71 participants 36 participants never prefer buying of generic, which is highest response about that statement. Participants do not have knowledge about side effects of generic drugs (34) or they think it occur rarely (25). Even they have not seen or heard publicity of generic drugs $(61.97 \%)$. They $(60.56 \%)$ opined that generic drugs are never prescribed in our country. Opinion about availability of generic medicine in pharmacies was variable, maximum responses (33.80) was that they don't know about it.

\section{DISCUSSION}

In this study, the term generic medicine is used to include medicine that is bioequivalent to a brand name (innovator or reference drug) medicine and contain the same strength in same type of dosage form after patent expiration. While generic medicines are permitted to differ from their equivalent branded medicine in terms of colour, size, shape and excipient ingredients, they must be able to demonstrate bioequivalence to the originator product in terms of the rate and extent of absorption. ${ }^{9}$

Result from this research showed that in majority of participants, they didn't know about generic medicine. This result contradicted the outcome of other studies. ${ }^{10}$ Lack of knowledge on generics was linked to the negative answers about perception of the patients about efficacy and safety of generic drugs. In present study participant didn't know about side effect of generic drugs and branded drugs. Possible explanation for that participant did not have enough information to understand the medicine they take. ${ }^{10}$

Generic formulations provide the same therapeutic effects like branded medicines at a much more economical price. ${ }^{11}$ Many doctors oppose brand substitution, believing generic medicines to be inferior to their branded counterparts. ${ }^{12}$ Physicians were the most likely to hold negative belief that side effects are more frequently caused by generic drugs in comparison to brand name drugs. ${ }^{13}$

The general population were most likely to have unfavourable attitude towards substituting branded medication with its generic equivalent. ${ }^{13}$ As it has been suggested that negative perception about generic medicine are major barrier to acceptance and widespread usage. ${ }^{9}$

Clinician and Pharmacist are in a position where they can easily transmit their expectations about the effectiveness and side effects of generic medicine to the patients under their care. ${ }^{14}$ The majority of consumers learn about generic medicine from a physician, and this medical advice is critical to consumer's decision to take generic medicine. ${ }^{15}$

In present study, majority of participants did not know about generic medicine and its implications, nor clinicians prescribe generic medicines. Generic medicines are cheaper alternative of innovator product and clinicians were not fully convinced that generic medicines are equivalent to branded ones, which can be reason for this negative response.

Negative perceptions of generic medicines among clinician could be lack of knowledge about generic medicine and their attitude that costly medicines are of better quality. So thus, it indicates that there is need of education as well as change of attitude among health providers.

Main limitation of this study is small sample size and small geographical area.

\section{CONCLUSION}

Limitation in knowledge and perception about generic medicines has been seen among participants. Improvement in knowledge about generic medicines is important factor to prefer generic medicine. Reduction in cost of drug will improve compliance, which will indirectly reflect in good response to drug therapy.

\section{Recommendations}

There is a need for interventions aimed at the health professionals and general populations to target misconceptions of inferior quality, safety and efficacy of generic medicines. So that patients can get benefit of costeffective generic drugs.

Funding: No funding sources

Conflict of interest: None declared

Ethical approval: The study was approved by the Institutional Ethics Committee

\section{REFERENCES}

1. Babar ZU, Stewart J, Reddy S, Alzaher W, Vareed P, Yacoub N, et al. "An evaluation of consumers knowledge, perceptions and attitudes regarding 
generic medicines in Auckland". Pharma world science. 2010;32(4):440-8.

2. Health Action International (HAI) Asia pacific. Position paper on accesss to medicine. 20004:1-9.

3. Thomas R, Vitry A. "Consumers perception of generic medicines in community pharmacies in Malaysia". South Med Rev. 2009;2(2):20-3.

4. Andersson K, Bergstrom G, Petzold MG, Carlstern A. "Impact of a generic substitution reform on patients and society sexpenditure for pharmaceuticals". Health Policy. 2007;81:376-84.

5. Shrank WH, Hoang T, Ettner SL, Glasssman PA, Nair $\mathrm{K}$, DeLapp D, et al. The implications of choice; Prescribing generic or preferred pharmaceuticals improves medication adherence for chronic conditions. Arch Intern Med. 2006;166:332-7.

6. Digne SV. A review of the safety of generic drugs. Transplant Proc. 1999;31(3 Asuppl):23-4.

7. AgenciaNacional de Vigilance Sanitaria. Medicamentio similar. ANVISA:2014.

8. Lira C, Oliveria J, Andrade M, Campanharo C, Vancini R. Knowledge, perception and use of generic drugs: a cross sectional study. Einstein. 2014; 12(3):267-73.

9. Alrasheedy AA, Hassali MA, Stewart K, Kong DC, Aljadhey $\mathrm{H}$, Mohamed Ibrahim M, et al. Patient knowledge, perceptions, and acceptance of generic medicines: a comprehensive review of the current literature. Patient Intell. 2014;6:1-29.
10. Hassali MAA, Shafie AA, Jamshed S, Ibrahim MIM, Awaisu A. Consumers views on generic medicines : a review of the literature. International $\mathrm{J}$ Pharmacy Practice. 2009; 17(2):79-88.

11. Howland RH. What makes a generic medication generic? J Psychosoc Nurs Ment Health Serv. 2009;47:17-20.

12. Shrank WH, Liberman JN, Fischer MA, Girdish C, Brennan TA, Choudhry NK. Physician perceptions about generic drugs. Annals of Pharmacotherapy. 2011;45(1):31-8.

13. S Colgan S, Faasse K, Martin LR, Stephens MH, Grey A, Petrie KJ. Perceptions of generic medication in the general population, doctors and pharmacists: a systematic review. BMJ open. 2015;5(12):e008915.

14. Faasse K, Petrie KJ. The nocebo effect: Patients expectations and medication side effects. Postgrad Med J. 2013;89:540-6.

15. Al-Gedadi NA, Hassali MA, Shafie AA. A pilot survey on perceptions and knowledge of generic medicines among consumers in Penang, Malaysia. Pharmacy Practice. 2008;6(2):93.

Cite this article as: Choulera MY, Dashputra AV, Borkar AS, Date AP. Knowledge and perception about generic drugs in patients coming to OPD of tertiary care centre. Int J Basic Clin Pharmacol 2018;7:1024-7. 